\title{
Homem sensível e mulher liberal: questões de sexualidade na telenovela $O$ grito de Jorge Andrade
}

Sabina R. Anzuategui

\section{Resumo:}

Análise dos personagens Kátia e Agenor, da telenovela O grito, de Jorge Andrade, exibida pela TV Globo entre 1975 e 1976. A obra faz parte de um pequeno conjunto, chamado na bibliografia especializada de novelas "alternativas" ou "experimentais". O artigo aborda as questões da masculinidade e do homossexualidade, comparando diferentes versões dos roteiros, e o vídeo do primeiro capítulo. Comentase também o tratamento desses temas em outras obras do dramaturgo, como o seu romance autobiográfico Labirinto, publicado pela primeira vez em 1978.

\section{Palavras Chave:}

Telenovela, Jorge Andrade, homossexualidade.

\begin{abstract}
:
It is an analysis of the characters Kátia and Agenor, from the telenovela $O$ grito, by Jorge Andrade, broadcasted by TV Globo between 1975 and 1976. The work is part of a small group called "alternative" or "experimental" by the specialized bibliography of telenovelas. The paper addresses issues of masculinity and homosexuality, comparing different versions of the scripts, and the video of the first episode. We also comment the treatment of these themes in other works of the playwright, as his autobiographical novel Labirinto , first published in 1978.
\end{abstract}

\section{Keywords:}

Telenovela, Jorge Andrade, homossexuality.

A telenovela $O$ grito foi escrita em 1975 pelo dramaturgo Jorge Andrade. Produzida e exibida pela TV Globo no horário das 22h, estreou depois do término de Gabriela, de Walter Durst, adaptação do romance de Jorge Amado. Num retrato alegórico da vida nas grandes cidades, a novela mostra o edifício Paraíso, em frente ao elevado Costa e Silva (o Minhocão), onde mora a maioria dos personagens. Lá vive Marta, uma ex-freira, viúva, mãe de um menino excepcional que grita desesperadamente durante a noite. O grito incomoda vários moradores, que convocam uma reunião de condomínio para expulsá-la do prédio.

A obra faz parte de um pequeno conjunto, chamado na bibliografia especializada de novelas "alternativas" ou "experimentais". O grito se diferencia do padrão do gênero pelo tom sóbrio e ação lenta, com muitos diálogos sobre questões abstratas (principalmente morais, sociológicas e psicológicas). Nas tramas paralelas, há vários personagens que lidam com aspectos da sexualidade. Entre eles, Kátia e Agenor são um caso interessante, em que se ressurgem temas presentes em outras obras do dramaturgo, como o romance autobiográfico Labirinto, publicado pela primeira vez em 1978.

Este artigo apresenta uma análise preliminar dos dois personagens (1). O recorte aqui apresentado - destacando as questões de sexualidade e gênero - deve ser compreendido em sua devida dimensão, no 
conjunto da obra: $O$ grito explora extensivamente a relação entre questões públicas (coletivas) e os problemas da vida privada. Os personagens da novela são vizinhos com poucas relações de amizade. Dois distúrbios forçam seu envolvimento: uma perturbação (o menino excepcional que grita durante a noite) e uma ameaça (alguém ouve as ligações telefônicas através de um interceptador). Tais eventos levam os moradores a enfrentar questões incômodas (culpas, segredos, traumas), e temer sua exposição. A novela passa à discussão dessas culpas: formam-se redes de inimizade e aliança, e os grupos opostos se enfrentam nas reuniões de condomínio. Dos sete principais segredos, quatro envolvem a sexualidade: um homem solteirão que desperta suspeitas de homossexualidade (Agenor); uma atriz que na infância testemunhou o estupro da mãe (Débora); a mulher que trai o marido com um jovem vizinho (Dorotéia); o morador da cobertura que tentou seduzir a filha do zelador (Edgard).

O problema de Agenor - o solteirão - é, entre todos, o que mais se relaciona à esfera pública - seu papel social como "homem". Não se sabe, a princípio, o que ele sente ou faz. Ele sai do apartamento à noite, com "roupas extravagantes", deixando o prédio pelo portão da garagem para não ser visto. Os pais não sabem aonde ele vai, imaginam apenas que ele "gosta do mundo dos artistas". Agenor parece sofrer, mas, diante deles, afirma sua escolha: não há problema em ser solteirão. Em contraponto, Kátia é a jovem bonita e solteira que se interessa por todos os homens: "de bigodes, sem bigodes, loiros ou morenos", "vigorosos ou frágeis","homens bem calibrados!" (capítulo 1).

\section{Resumo do enredo}

Estes são os principais eventos que envolvem Kátia e Agenor (2).

Kátia (interpretada por Yoná Magalhães) é uma jovem secretária, que divide o apartamento com uma amiga. Cresceu num orfanato, e sobreviveu ao incêndio do edifício Joelma (3). Este trauma reforçou sua determinação de gozar a vida: "É só ficar preso num prédio incendiado, cercado pela morte por todos os lados, uma ilha humana ansiando pela vida além das labaredas! Quando a gente consegue escapar, a brisa que bate em nosso rosto é como se fosse o beijo de Deus!" (capítulo 58). Kátia gosta "de ver um homem se vestir... e se despir também!" (capítulo 103). Ela odeia "os moralistas que vivem querendo consertar o homem, o mundo!" (capítulo 99). Muitos moradores não aprovam seu comportamento liberal. A jovem tem um sonho: ficar nua na janela "e provocar um congestionamento monstro no Minhocão!" (capítulo 123). Ela realiza esse sonho nos últimos capítulos.

Agenor é um executivo, solteiro, que mora com os pais, Sebastião e Branca (interpretados respectivamente por Rubens de Falco, Castro Gonzaga e Ida Gomes). A família tem fazendas no interior, mas os velhos decidiram mudar para a capital por causa do comportamento do filho: "Agenor já está com mais de trinta anos... e ainda não foi na zona! (...) Homem gosta é de mulher! (atônito) Com mais de trinta anos, Branca. Já pensou?" (capítulo 22). Branca diz que o casal só voltará ao interior quando o filho casar: "Só com seu casamento, seu pai pode provar a si mesmo e aos amigos que não é verdade o que pensam de você" (capítulo 18). Agenor se defende: "Não é vergonha ser solteirão... e pretendo continuar!" (capítulo 14).

Agenor sai à noite com "roupas extravagantes" (capítulo 2). Usa a porta da garagem para não encontrar outros moradores. Mas Francisco, o zelador, tem o hábito de verificar arranhões nos carros toda noite. Agenor teme ter sido visto. Apesar das escapadas noturnas, é solitário e liga constantemente para o CVV (capítulos 5, 85, 90, 117).

A primeira aproximação acontece por iniciativa do pai, Sebastião. Ao perceber o comportamento exuberante de Kátia, Sebastião a procura e oferece Cr\$ 20.000: "Meu filho vai casar... mas antes precisa conhecer uma dona formosa e com uma certa experiência!”. Kátia recusa: “Cada um é o que é! E daí? Respeite seu filho e respeite a mim!" (capítulo 27). Mas Kátia se comove com o caso, e faz contato com uma prostituta, que deseja apresentar a Agenor como se fosse uma amiga. Ela se aproxima dele, que a convida para visitar o estúdio do pintor Wesley Duke Lee. Nessa visita, Kátia descobre que Agenor frequenta o lugar há um mês, para observar o quadro "Os mil olhos da verdade", que mostra uma figura andrógina: "os ombros são masculinos, mas tem seios. As cadeiras são estreitas, mas tem sexo feminino"(capítulo 42). 
A partir desse encontro, Kátia se comove com Agenor, por quem sente uma "coisa estranha", "uma espécie de piedade" (capítulo 71). Ao comentar o caso com Orlando - jovem médico, seu parceiro eventual - este faz uma ironia, dizendo que Kátia quer "bancar a samaritana sexual" (capítulo 58).

A liberdade de Kátia atinge um limite: ao aceitar o convite de seu chefe para sair à noite, ela descobre, ofendida, que se trata de um programa com vários homens e prostitutas. Kátia pede demissão, e procura Agenor, precisando de um novo emprego. Ele a ajuda, e passam a trabalhar juntos também em casa, além do expediente.

Agenor se encanta com a "alegria de viver" de Kátia. Os dois se aproximam lentamente. Kátia convida Agenor para visitá-la certa noite, e ele hesita entre a vontade e o medo do fracasso. A dúvida é mostrada longa e detalhadamente (o tempo diegético da novela dura uma semana, estendida por 125 capítulos). Finalmente ele se deixa seduzir e sente "qualquer coisa como se fosse explodir...! Como um grito parado dentro do peito!" (capítulo 99).

Quando os dois passam a noite juntos no apartamento dela, Sebastião (o pai), agachado no corredor, observa tudo pelo buraco da fechadura. Depois de consumada a relação, ele sai pela rua, "dirigindo-se aos que passam": "Meu filho conseguiu!... ele conseguiu!... Vocês compreendem...?! Eu tinha certeza...!" (capítulo 100).

No apartamento, Sebastião tem fantasias sobre a masculinidade do filho. Imagina Kátia grávida, o quarto "repleto de crianças". Na fantasia aparece o síndico Otávio, que "fica de quatro". Sebastião grita: “Tudo neto meu! (...) E filhos de Agenor! É você que não tem nenhum! Não dá no couro! (...) Montem nele! Montem!". Duas crianças "sobem nas costas de Otávio e todo mundo ri” (capítulo 105).

Depois da noite juntos, Agenor decide casar com Kátia. Agora é Branca (a mãe) quem fantasia. Imagina Kátia "pintada como uma prostituta vagabunda", rindo debochada: "Eu vim buscar o teu filhinho!" (capítulo 110). Para celebrar o futuro casamento, Agenor dá a Kátia as jóias da família (capítulo 118).

Paralelamente a essa aproximação sentimental, os dois personagens enfrentam os conflitos no edifício, e precisam se posicionar em relação a Marta (a mãe do menino doente, que sofre ameaça de expulsão). Kátia a defende publicamente desde o início. Agenor prefere não se envolver.

Um diálogo entre os dois, no capítulo 83, demonstra como a obra relaciona as decisões públicas e privadas dos personagens:

KATIA - Nós vivemos no mundo, não no paraíso!

AGENOR - (Irônico) Pelo menos o edifício chama-se paraíso!

KATIA - Se compreendessem, tolerassem mais os outros... talvez pudesse se transformar num paraíso! Depois... acho que é um problema da liberdade de cada um... de ser o que é! Expulsam dona Marta por causa dos gritos, depois expulsam a mim por um motivo qualquer, ou você ou outro qualquer. Acha que podemos permitir isto?

AGENOR - (Retesado) Creio que não.

(...)

[KATIA] - Reclamam dos gritos do filho de dona Marta, do trânsito, da poluição do ar... nem sei o que mais! Mas fingem ignorar a poluição da miséria nesta cidade que solta gritos muito piores. E outros gritos por aí!

AGENOR - (Meio doloroso) Quer saber minha opinião? Eu não voto... mas estou contra dona Marta! Você fala em liberdade, em direito...! Pois eu tenho direito de não querer ouvir aqueles gritos. (Abaixa a cabeça) Já bastam os meus!

KATIA - (Penalizada e sem poder resistir) Posso ajudar você a esquecer os seus. Se não esquecer, pelo menos a suportar!

AGENOR - Pode?!

KATIA - Posso!

AGENOR - (Sem olhar Kátia) Conhece quais são os meus gritos?

KATIA - (Firme) Conheço!

AGENOR - E não me despreza? 
KATIA - Nem um pouco. Aceito cada um, como cada um é! É assim que quero ser aceita (4).

\section{Diferentes versões do roteiro}

O projeto sobre a novela se concentrará principalmente nos roteiros, a partir de duas fontes: as cópias digitalizadas do Centro de Documentação da Rede Globo - um conjunto de 125 capítulos - e os originais do acervo da família de Jorge Andrade - que têm 134 capítulos.

As cópias da TV Globo foram digitalizadas a partir do microfilme, realizado em 1976, logo após a exibição da novela. Nesse material percebem-se correções manuscritas em várias páginas, com nova numeração dos capítulos. As alterações ocorrem principalmente ao final da novela, mostrando o número original riscado ou apagado, e um novo número escrito manualmente, com a indicação "(novo)".

Outra versão dos roteiros foi consultada no acervo da família, em posse da filha de Jorge Andrade, Camila Franco. É um conjunto de 134 capítulos, datilografados numa máquina diferente, com margens e formatação em outro padrão. Ainda não consegui identificar o motivo dessa mudança. Uma hipótese é que a TV Globo, ao receber os capítulos do autor, fizesse uma nova cópia, passada a limpo, depois de modificações de produção ou da censura.

A nova numeração, em geral, adianta o surgimento das cenas. Por exemplo, a cena em que Agenor sai do apartamento da mãe, perfumado, para encontrar Kátia na noite definitiva: no original do autor, tal cena aparece no capítulo 107. Nos roteiros da TV Globo, a mesma cena está no capítulo 93.

O Cedoc autoriza anotações manuscritas, mas não é possível imprimir ou copiar os originais. Consegui apenas algumas folhas avulsas, com a autorização da responsável, Laura Martins. Será demorado fazer uma comparação extensiva das alterações, pois a visita ao Cedoc necessita de agendamento prévio, e há poucos horários disponíveis. Numa verificação preliminar, comparando uma página da cena em que Sebastião fantasia sobre a fertilidade do filho, não encontrei alterações no texto. As questões que se colocam são: além dos cortes evidentes, pois a novela foi reduzida em nove capítulos, haveria cortes pequenos (frases ou palavras excluídas)? Quem datilografou a segunda versão do roteiro?

Para a pesquisa final, serão entrevistadas algumas pessoas para compreender melhor a organização da produção da TV Globo nessa época, e organizar um índice das diferenças entre as duas versões. Mas a tese deve privilegiar a análise do roteiro original do autor. Tal escolha se justifica pela opção inicial da pesquisa, ou seja, o trabalho do dramaturgo no sistema de produção de uma telenovela.

Neste artigo, chamarei o texto consultado no acervo da família como "roteiro original", e o material disponível no Cedoc da TV Globo como "roteiro revisado".

\section{Entre o roteiro e o vídeo}

Outra diferença que se destaca, no personagem de Agenor, acontece entre o roteiro e o vídeo do capítulo finalizado. No acervo da ECA-USP há uma cópia do primeiro e do último capítulo da novela. Consideramos esse material suficiente para os propósitos dessa pesquisa, e não buscamos outros capítulos em vídeo na TV Globo. Como a tese deverá se concentrar no texto do autor, a comparação com as imagens editadas devem apontar questões, sem esgotar tal assunto, que poderá ser desenvolvido em pesquisa posterior.

$\mathrm{Na}$ comparação entre o roteiro e o vídeo do primeiro capítulo, é possível perceber algumas diferenças, comentadas a seguir.

$\mathrm{Na}$ primeira cena em que Agenor aparece, há pequenas mudanças entre o roteiro e o vídeo. A situação começa na "escadaria repleta de estudantes" do Curso Objetivo, quando Rogério (um jovem arquiteto) vai buscar sua namorada Marina, que ali estuda. O texto diz:

Rogério pega em sua mão e os dois saem andando pela Avenida Paulista. A câmara focaliza a avenida e seus edifícios, fixando-se num prédio de vidraças fumê. A câmara, em ZOOM, mostra Agenor parado atrás de uma das vidraças. CORTE.

8 - SALA DE AGENOR. TARDE.

Corte para Agenor parado diante da vidraça e observando Marina e Rogério, ainda parados na calçada. Os dois estão rindo, felizes. Agenor, impecavelmente vestido, contrai o rosto, amargurado. 
Percebe-se que a felicidade de Rogério não lhe faz bem. Como um "voyeur", ele examina os dois namorados, fixando-se no rosto de Rogério. Estampa-se em seus olhos, um secreto e inconfessável desejo. A secretária entra (5).

No capítulo em vídeo, a situação é simplificada. Há a imagem de Rogério e Marina caminhando na rua, e um corte seco leva ao rosto angustiado de Agenor, dentro do escritório. Não existem dois planos sugeridos pelo roteiro: o zoom da rua para o rosto de Agenor atrás da vidraça, e a imagem de Marina e Rogério vistos de dentro do escritório, através da vidraça. Esses dois planos marcariam com clareza a direção do olhar de Agenor. O roteiro se detém nesse olhar e o qualifica, dizendo que ele "examina" os namorados "como um voyeur", e que seus olhos estampam um "secreto e inconfessável desejo".

Observando o capítulo completo em vídeo, acredito que tal simplificação tenha sido motivada por questões de produção, e não por censura ao conteúdo da cena. Para se realizar a cena conforme descrita no roteiro, seria preciso: 1) encontrar uma janela de escritório visível da rua em que passa Rogério, ao alcance da lente de zoom; 2) iluminar o interior do escritório e corrigir os reflexos na vidraça; 3) levar o ator Rubens de Falco a esta locação, para gravar o plano. Um procedimento parecido seria necessário para fazer o plano descrito na cena 8, mostrando Rogério e Marina vistos de dentro do escritório. Naturalmente, essa opção é muito mais trabalhosa do que a versão realizada: um plano simples de Rogério e Marina na rua; e outro plano simples de Agenor no escritório, gravado em estúdio.

$\mathrm{Na}$ segunda cena em que Agenor aparece, a diferença entre o roteiro e o capítulo em vídeo é maior, pois as imagens ampliam a situação descrita no roteiro, reforçando o subtexto que havia sido diminuído da primeira vez.

A situação começa com Sebastião e Branca, os pais, no "living" do apartamento, conversando. A conversa sugere indiretamente o problema do filho. Então o roteiro indica:

CORTE para Agenor no quarto, sentado diante do espêlho. Branca entra.

BRANCA - Vai sair, meu filho?

AGENOR - Vou.

BRANCA - Não volte tarde, filho!

AGENOR - Tenho 40 anos. Sei o que faço!

Branca fecha a porta. Angustiado, Agenor encosta a cabeça na toalete.

CORTE (6).

O vídeo, nesse caso, é muito mais detalhado que o roteiro. A cena completa tem aproximadamente 2 minutos e 40 segundos (7). Na prática de produção, considera-se que, em média, uma página de roteiro equivale a 1 minuto de imagens editadas. Assim, o breve diálogo de Agenor com sua mãe deveria sugerir, se gravado como descrito, cerca de 20 segundos de imagem.

Mas uma ampliação é realizada, pelo prolongamento da frase "angustiado, Agenor encosta a cabeça na toalete". A cena mostra os seguintes planos:

1. Agenor de perfil, em primeiríssimo plano, desfocado. Ao fundo abre-se a porta, e sua mãe entra. Segue-se o diálogo previsto no roteiro, com leves alterações. Branca sai e fecha a porta, o foco corrige para mostrar o rosto de Agenor nitidamente. Nesse momento começa a trilha musical, com piano e uma espécie de assovio, de clima misterioso.

2. Plano um pouco mais aberto, mostrando o torso de Agenor, de roupão, olhando-se no espelho. Em zoom, o enquadramento fecha até um superclose dos olhos, nariz e parte do bigode do ator. Seus olhos tremem e ele vira o rosto, afastando-se do espelho. Esse plano dura 34 segundos, com a mesma trilha musical do plano anterior.

3. Em outro ângulo, o rosto de Agenor ainda em primeiro plano. Ele dá alguns passos. Abre-se o quadro, mostrando o quarto pela primeira vez. Ao fundo há um armário decorado com imagens de corpos masculinos (período grego ou renascimento, a verificar). A cama tem um lençol vermelho, e um cobertor com padrão animal (girafa ou felino). Agenor caminha tenso até o armário, encosta-se e dá um soco.

4. Primeiro plano da mão de Agenor, no movimento do soco. Suas mãos tremem, ele dá quatro socos mais fortes. Em seguida as mãos relaxam lentamente, e ele estende os dedos na superfície do armário. A trilha musical muda, entrando novos acordes e uma leve percussão. As mãos de Agenor se 
aproximam de seu rosto, num gesto de dançarino.

5. Num plano médio, Agenor se afasta do armário. Suas mãos descem pelo corpo em direção à alça do roupão. Ele se vira lentamente para o centro do quarto, ficando de frente para a câmera. Com o corpo ereto, ele abre o roupão. $\mathrm{O}$ enquadramento fecha novamente em seu rosto. Ele tem o olhar altivo e esboça um sorriso malicioso.

A partir da descrição das duas cenas, percebe-se que se, na primeira aparição de Agenor, o "secreto e inconfessável desejo" foi bastante reduzido. Mas ele não foi eliminado do capítulo, reaparecendo mais tarde, com bastante destaque e didatismo. Como os interiores das novelas são gravados em estúdio, a equipe teve a oportunidade de explorar o subtexto, trazendo-o para a superfície, em condições mais confortáveis de gravação.

\section{Fragilidade e homossexualidade na obra de Jorge Andrade}

Em algumas peças teatrais de Jorge Andrade, e também em seu romance autobiográfico, aparecem várias situações que mostram conflitos da masculinidade na juventude. O homossexualidade aparece como suspeita, acusação injusta, na voz do pai que não compreende o filho. O problema desses personagens, duplos do autor, é se descobrir como homens não masculinos, filhos sensíveis, que gostam de arte e leitura em vez de prostíbulos, que passam o dia na fazenda entre mulheres - mãe, avós e tias. São jovens que se recusam a matar um animal caçado, e são acusados de pouca hombridade pelo pai, macho orgulhoso. Nas peças e no romance, esse confronto com o mundo patriarcal é tenso e sóbrio.

Como indicado pela professora Catarina Sant'Anna em parecer para minha banca de qualificação (8), o romance Labirinto descreve a primeira experiência sexual do autor, com sua prima samaritana (9). A jovem que se aproxima do adolescente e o seduz, revelando a ele mesmo o homem escondido em seu interior, assemelha-se a Kátia, a "samaritana sexual". A prima entra no quarto do rapaz quando a família está viajando, e afasta seu medo de não ser homem, como sugerido em conflitos com a família (10).

$\mathrm{Na}$ obra escrita para TV, tal fragilidade recebe indícios evidentes de homossexualidade. Para resgatá-lo da vergonha e da fraqueza, surge a mulher vibrante, sem medo da moral alheia, com seus seios aerodinâmicos. Essa regeneração em forma de final feliz parece hoje improvável e conservadora, se interpretada pelos princípios de afirmação do movimento gay. Mas Jorge Andrade estava muito distante desse tipo de militância. Sua preocupação se relaciona mais diretamente à falência da figura masculina e paterna, como aparece em outros dramaturgos do período. Mais especificamente, podem ser encontrados indícios da mesma preocupação na obra $O$ espigão, de Dias Gomes, exibida em 1974, em que dois importantes personagens masculinos têm problemas de ordem sexual: um é estéril, e o outro se torna impotente depois dos primeiros encontros, precisando variar constantemente de mulher (não por desejo, mas por medo do fracasso). Uma reportagem da revista Veja sobre sexologia, publicada em 1975, também destaca a impotência, enquanto outras "disfunções" são tratadas com menor atenção.

Mas é importante dar a dimensão justa desse tema no conjunto da novela $O$ grito. A obra discute principalmente questões morais, catalisadas pela figura de Marta. $\mathrm{O}$ texto não desenha personagens bons ou maus, mas, através de longas discussões dos problemas que se apresentam, vai estabelecendo parâmetros do que é certo e errado. Kátia está do lado certo - ela é compreensiva e generosa com Agenor, e age do mesmo modo com Marta.

Agenor, que esconde os próprios medos, também se esconde quando Marta precisa de apoio. Um painel didático é montado: ele não erra por forças essenciais, de seu ser ou do mundo: ele erra porque sofre, e tem medo. Quando Kátia o compreende, ele deixa de se sentir ameaçado, e passa a agir bem.

Este diálogo acontece no encontro definitivo dos dois, quando a relação se consuma:

Kátia - Encontrei um homem! Isto é tudo!

Agenor - (consigo mesmo) Um homem.

Kátia - Um homem limpo como sempre desejei encontrar! (beija o rosto de Agenor) Um homem com 'H' maiúsculo!

Agenor - (já fascinado) Kátia.

Kátia - Um homem sem mente suja... (beija o peito de Agenor)... e com um coração sem ódios! 
Agenor - (beija o rosto de Kátia) Você é maravilhosa... não sei... sinto qualquer coisa como se fôsse explodir...! Como um grito parado dentro do meu peito!

Kátia - (beija Agenor) Pois deixe que ele saia! Eu quero ouvir este grito! Agenor - (ansioso e sentindo-se em fogo) É um grito... É um grito...

Kátia - Tenho certeza que é de amor...

De repente, Agenor toma a ação e começa a beijar Kátia. Kátia, sensual, deixa a cabeça cair para trás, aprisionando Agenor definitivamente (11).

Numa novela em que os pares românticos são tramas secundárias, o amor se apresenta assim: a redenção possível entre uma mulher independente e um homem sem masculinidade. No prosseguimento da pesquisa, buscarei analisar essas questões com maior detalhamento.

\section{Bibliografia:}

AMÂNCIO, Moacir; PUCCI, Claudio. "O labirinto Jorge e os outros". Folha de S. Paulo, 16/06/1978.

ANDRADE, Jorge. $O$ grito. Roteiro microfilmado. Acervo Centro de Documentação da TV Globo (Cedoc), Rio de Janeiro, 1976.

ANDRADE, Jorge $O$ grito. Roteiro original. Acervo Camila Franco, São Paulo, 1976.

ANDRADE, Jorge Marta, a árvore e o relógio. $2^{\mathrm{a}}$. ed. São Paulo: Perspectiva, 1986.

ANDRADE, Jorge. Labirinto. Rio de Janeiro: Paz e Terra, 1978.

AZEVEDO, Elizabeth. Recursos estilísticos na dramaturgia de Jorge Andrade. São Paulo: ECA-USP, 2001 (tese de doutorado).

DUTRA, M. H. "Um grito absurdo". Veja, 12/11/1975.

MAIA, P. "Um rótulo diferente para o mesmo produto". Jornal do Brasil, 04/04/1976. Fonte: Banco de Dados TV-Pesquisa, PUC-Rio.

REVISTA VEJA. "A sexologia e o seu mundo", 13/08/1975.

SANT'ANNA, Catarina. Metalinguagem e teatro: a obra de Jorge Andrade. Cuiabá: EdUFMT, 1997. STEEN, Edla van. Viver \& escrever. Volume 3. 2a . ed. Porto Alegre: L\&PM, 2008.

TAGÉ, Terezinha. Jorge Andrade, repórter asmodeu. São Paulo: ECA-USP, 1989 (tese de doutorado).

\section{Notas:}

Trabalho apresentado na I Jornada Discente do Programa de Pós-Graduação em Meios e Processos Audiovisuais da Escola de Comunicações e Artes da Universidade de São Paulo (ECA-USP), realizada em novembro de 2010.

(1) Informações mais gerais sobre a telenovela podem ser consultadas no artigo "O roteiro de $O$ grito, telenovela de Jorge Andrade", de minha autoria, apresentado no II Seminário Histórias de Roteiristas, promovido pela Universidade Mackenzie, em novembro de 2010.

(2) A numeração dos capítulos é baseada nos roteiros microfilmados do acervo da TV Globo. Como explicado adiante, a numeração dos originais no acervo da família é diferente. Escolhi a numeração dos roteiros da emissora, para comentar o enredo, porque representa com maior probabilidade o que foi exibido. Mas tal informação só poderá ser confirmada com a verificação dos capítulos em vídeo, o que está além dos objetivos desta pesquisa.

(3) Tragédia ocorrida na cidade de São Paulo, em fevereiro de 1974, em que morreram 187 pessoas (CAVERSAN, 2003).

(4) Transcrito do roteiro original, conforme explicado abaixo.

(5) A cena é descrita igualmente no roteiro original e no revisado.

(6) Transcrito do roteiro original 
(7) Não é possível contar exatamente, pois a cópia tem um salto.

(8) Realizada em setembro de 2010.

(9) No romance, o narrador chama-se Jorge, e tem muita proximidade biográfica com Jorge Andrade.

Mas a obra não é uma autobiografia, e não deve ser compreendida como um depoimento preciso, mas sim como uma criação literária baseada na experiência do autor.

(10) A cena acontece entre as páginas 170 e 172 do romance.

(11) Transcrito a partir do roteiro revisado.

\section{Mini Currículo :}

Doutoranda do Programa de Pós-Graduação em Meios e Processos Audiovisuais da Escola de Comunicações e Artes da Universidade de São Paulo (ECA-USP). 